\title{
(2) OPEN ACCESS \\ CIC de novo loss of function variants contribute to cerebral folate deficiency by downregulating FOLR1 expression
}

\author{
Xuanye Cao, ${ }^{1}$ Annika Wolf, ${ }^{2}$ Sung-Eun Kim, ${ }^{3}$ Robert M. Cabrera, ${ }^{1}$ \\ Bogdan J. Wlodarczyk, ${ }^{1}$ Huiping Zhu, ${ }^{4}$ Margaret Parker, ${ }^{3}$ Ying Lin, ${ }^{1}$ John W. Steele, ${ }^{1,5}$ \\ Xiao Han, ${ }^{1}$ Vincent Th Ramaekers (1) , ${ }^{6}$ Robert Steinfeld, ${ }^{2,7}$ Richard H. Finnell, 3,8,9 \\ Yunping Lei (D) ${ }^{1}$
}

\begin{abstract}
- Additional material is published online only. To view please visit the journal online (http://dx.doi.org/10.1136/ jmedgenet-2020-106987).
\end{abstract}

For numbered affiliations see end of article.

\section{Correspondence to}

Dr. Yunping Lei, Baylor College of Medicine, Houston, Texas,

USA; yunpinglei@gmail.com Dr. Richard H. Finnell; richard.finnell@bcm.edu Dr. Robert Steinfeld; Robert.Steinfeld@kispi.uzh.ch

$X C, A W$ and S-EK contributed equally.

Received 10 March 2020 Revised 27 May 2020

Accepted 5 June 2020 Published Online First 20 August 2020

Check for updates

(C) Author(s) (or their employer(s)) 2021. Re-use permitted under CC BY-NC. No commercial re-use. See rights and permissions. Published by BMJ.

To cite: Cao X, Wolf A Kim S-E, et al. J Med Genet 2021:58:484-494.

\section{ABSTRACT}

Background Cerebral folate deficiency (CFD) syndrome is characterised by a low concentration of 5-methyltetrahydrofolate in cerebrospinal fluid, while folate levels in plasma and red blood cells are in the low normal range. Mutations in several folate pathway genes, including FOLR1 (folate receptor alpha, FR $\alpha$ ), DHFR (dihydrofolate reductase) and PCFT (proton coupled folate transporter) have been previously identified in patients with CFD.

Methods In an effort to identify causal mutations for CFD, we performed whole exome sequencing analysis on eight CFD trios and identified eight de novo mutations in seven trios.

Results Notably, we found a de novo stop gain mutation in the capicua (CIC) gene. Using 48 sporadic CFD samples as a validation cohort, we identified three additional rare variants in CIC that are putatively deleterious mutations. Functional analysis indicates that $\mathrm{CIC}$ binds to an octameric sequence in the promoter regions of folate transport genes: FOLR1, PCFT and reduced folate carrier (SIC19A1; RFC1). The CIC nonsense variant (p.R353X) downregulated FOLR1 expression in HeLa cells as well as in the induced pluripotent stem cell (iPSCs) derived from the original CFD proband. Folate binding assay demonstrated that the P.R353X variant decreased cellular binding of folic acid in cells.

Conclusion This study indicates that CIC loss of function variants can contribute to the genetic aetiology of CFD through regulating FOLR1 expression. Our study described the first mutations in a non-folate pathway gene that can contribute to the aetiology of CFD.

\section{INTRODUCTION}

Cerebral folate deficiency (CFD) is defined as any neurological syndrome associated with low 5-methyltetrahydrofolate (5-MTHF) concentrations in cerebrospinal fluid (CSF), while folate concentrations in serum are typically in the low normal range. ${ }^{1}$ In humans, the folate concentration in the CSF is normally $\geq 1.5$-fold higher than in serum. As folate is essential for normal development and production of the biogenic amines and pterins in the central nervous system, prenatal and postnatal folate deficiency produces a variety of neurological symptoms, including intellectual disability, epilepsy, ataxia and pyramidal tract signs. ${ }^{2}$ Folate is absorbed into the bloodstream via the gastrointestinal tract mainly through two uptake systems: the reduced folate carrier 1 (RFC1; SLC19A1) and the proton-coupled folate transporter (PCFT). ${ }^{3}$ From the bloodstream, folate binds to the folate receptor alpha (FR $\alpha / F O L R 1)$ on the basolateral endothelial surface of the choroid plexus. Through receptormediated endocytosis and transcytosis, folate is then transported across the blood-CSF-barrier into the CSF. ${ }^{4}$ FOLR1 is highly expressed in the choroid plexus, and it has a higher affinity to folic acid (FA) at neutral $\mathrm{pH}$ compared with other folate transporters, such as PCFT and RFC1. ${ }^{5}$ These two characteristics are important factors in building and keeping higher folate concentrations in the CSF than in serum. Previous studies demonstrated that dysfunctional FOLR1, such as that which could be the result of either FOLR1 mutations ${ }^{67}$ or FOLR1 autoantibodies, ${ }^{8}$ can result in CFD. Mutations in other folate related genes, such as $D H F R^{9}{ }^{10}$ and PCFT, ${ }^{11} 12$ are also reported to be associated with low 5-MTHF CSF concentrations. We previously reported a patient carrying a de novo truncating CIC mutation. ${ }^{13}$ The patient presented with a paediatric B-cell acute lymphoblastic leukaemia (B-ALL) and was treated with methotrexate (MTX). She developed a spectrum of neurobehavioral disorders including signs of autistic spectrum disorder, seizures, loss of language and motor skills and had CFD, even after cancer remission and the discontinuation of MTX treatment.

The CIC gene was originally discovered in Drosophila, where it was shown to be highly expressed in the head and tail region, ${ }^{14}$ which resulted in the naming of it 'head and tail' or 'capicua' in Catalan. It is a transcriptional repressor of the high mobility group (HMG)-box family, which binds a specific octameric DNA sequence, $\mathrm{T}(\mathrm{G} / \mathrm{C}) \operatorname{AATG}(\mathrm{A} / \mathrm{G}) \mathrm{A}$, in the genome via their HMG-box and C1 domain. ${ }^{15}$ CIC is known to be transported into the nucleus by KPNA3, a nuclear importin protein that can interact with CIC at its C-terminal nuclear localisation signal domain. ${ }^{16}$ It was found to function downstream of the EGFRTK-RAS-ERK-MAPK signalling pathway to control embryonic pattern formation. ${ }^{14}$ Recently, 
studies also indicated CIC influences Toll/Interleukin-1 signalling. ${ }^{17}$ The most well-known CIC downstream target genes include polyomavirus enhancer activator 3 family members genes, ETV1, ETV4 and ETV5 as well as matrix metalloproteinase $9(M M P 9)^{18}$ and MMP24. ${ }^{19}$ In the absence of EGFR-ERK signalling, CIC binds to and represses those genes, while activation of the pathway results in inactivation of CIC through phosphorylation induced degradation or relocalisation from the nucleus to the cytoplasm..$^{20-23}$ In mammals, CIC forms a transcriptional repressor complex with ataxin-1, a gene that contributes to the pathogenesis of spinocerebellar ataxia type $1 .^{24}$ Conventional Cic knockout $(\mathrm{KO})$ mice present with omphalocele, abnormally small litter size and lung differentiation defects that result in perinatal lethality. ${ }^{18} 25$ In early development, mice with a conditional CIC KO display impaired forebrain neurodevelopment, resulting in hyperactivity, decreased learning ability and impaired memory. ${ }^{13}$ In adult mice, systemic conditional CIC inactivation induces T-cell acute lymphoblastic lymphoma. CIC was also reported to modify peripheral immune tolerance by suppressing aberrant activation of adaptive immunity. ${ }^{26}$ In humans, CIC mutations have been associated with several diseases, including neurobehavioral phenotypes, ${ }^{13}$ oligodendroglioma, ${ }^{27}$ lung carcinoma ${ }^{19}$ and prostate cancer. ${ }^{28}$

Although studies have reported that mutations in human CIC are strongly associated with ALL and neurobehavioral phenotypes, studies to date have failed to determine whether $\mathrm{CIC}$ mutations contribute to the aetiology of CFD. In fact, there are no comprehensive trio-based genetic studies on patients with CFD. Since the aforementioned patient who carries the truncated CIC mutation does not seem to carry any rare variant in known CFD genes (FOLR1, PCFT and RFC1) in our whole exome sequencing (WES) dataset, we propose that the truncated CIC protein may play a role in CFD progression. Thus, CFD may be caused from genetic factors other than variants in known folate transport genes. In order to better understand the aetiology of CFD, a comprehensive genetic profiling of patients with CFD is definitely required, followed by a validation of whether CIC gene mutation contributes to CFD. Herein, we performed WES on eight CFD trios and 48 sporadic patients with CFD. We identified eight de novo mutations in seven different trios. Among the cohort of 48 sporadic patients with CFD, we identified another three CIC rare deleterious mutations. Finally, we performed functional assays on the de novo truncated CIC variant and showed that the truncated CIC dysregulates the folate transport genes in HeLa and patient-derived human iPSCs. Overall, our results provided the first trio-based genetic analysis on patients with CFD and enhanced our understanding of a new CFD aetiology.

\section{MATERIALS AND METHODS Human subjects}

The original CFD proband in this study was collected through self-referral by the mother of the patient. An additional 48 cases were collected with (10) or without (38) our ability to obtain parental biological samples. Folate concentrations in CSF were measured at the treating hospitals. DNA samples of 48 CFD cases from various genetic and neuropaediatric clinics in Germany, Finland, Italy, Switzerland, The Netherlands, UK and the USA were reported in our previous publication. ${ }^{7}$ This study was approved by institutional review board of The University of Texas at Austin. All samples were collected with written informed parental consent.

\section{Sequencing analysis of DNA samples}

DNA sequencing libraries were built using NEBNext Ultra DNA Library Prep Kit (New England Biolabs) following protocols as described by the manufacturer (V.3.0). The Agilent SureSelect Human All Exon V5 (Agilent Technologies) was used for exome enrichment. Libraries were sequenced by the Genome Sequencing and Analysis Facility at University of Texas at Austin using an Illumina Hi-Seq 2000 platform (Illumina). Next generation sequencing data were analysed following GATK Best Practices (https://software.broadinstitute.org/gatk/ best-practices/). Briefly, FASTQ format data were mapped to hg19 using BWA alignment software, ${ }^{29}$ sorted and indexed by SAMtools, ${ }^{30}$ base recalibrated by GATK $^{31}$ and duplicate reads removed by Picard software (https://broadinstitute.github. io/picard/). Variants were called using GATK HaplotypeCaller methods. De novo variant analysis was performed by TrioDeNovo software. ${ }^{32}$ Variants annotation was performed with Annovar. ${ }^{33}$ Sanger sequencing was performed following previously published primers and protocols. ${ }^{34} \mathrm{CIC}$ sequencing primers are in online supplementary table 1. Polyphen2, SIFT and CADD scores were used for predicting variants' function. ${ }^{35-37}$ The gnomAD database was used for examining the allele frequency of each mutants. ${ }^{38}$

\section{Plasmid preparation and siRNA information}

GFP-CIC and HA-KPNA3 plasmids were provided to us by $\mathrm{Dr}$ Carol MacKintosh at the University of Dundee. CIC variant was introduced into the GFP-CIC plasmid using the GeneArt Site-Directed Mutagenesis System (Cat\# A14604, Thermofisher Scientific). Ataxin-1 plasmids were provided by Dr Huda Zoghbi at Baylor College of Medicine (Addgene Cat\# 48189).

Full-length human CIC and CIC variant were inserted via EcoRI/SalI into the expression vector pLVX-IRES-puro (Takara Bio) containing an EGFP ORF. Vectors for production of lentiviral particles pMD2.G and psPAX2 were from Addgene (plasmids Cat\# 12259, Cat\# 12260; deposited by Didier Trono). pGL3basic was obtained from a commercial source (Promega). FOLR1 promoter region was PCR amplified and inserted into pGL3basic by subcloning. ON-TARGET plus SMARTpool targeting the CIC gene, including four individual siRNAs (GCUUAGUGUAUUCGGACAA, CGGCGCAAGAGACCCGAAA, GAGAAGCCGCAAUGAGCGA and CGAGUGAUGAGGAGCGCAU) were purchased from Dharmacon as previously reported. ${ }^{16}$ The scrambled universal negative siRNA control was purchased from Sigma-Aldrich (Cat\# SIC005).

\section{Generation of stable cell lines and subcellular localisation analysis}

For virus production, HEK293T cells were cotransfected with pMD2.G, psPAX2 and pLVX-GFP-puro plasmids containing CIC WT or CIC mutant p.R353X using a calcium phosphate method. After 48 hours, viral supernatants were collected, passed through a $0.45 \mu \mathrm{m}$ PES-membrane filter and precipitated using polyethylene glycol 6000. Lentivirus infection was performed in the presence of $5 \mu \mathrm{g} / \mathrm{mL}$ polybrene. Infected HeLa and Caco- 2 cells were selected with puromycin $(1 \mu \mathrm{g} /$ $\mathrm{mL})$. HeLa cells and Caco-2 cells stably expressing GFP-CIC wildtype, GFP-CIC p.R353X or GFP (control) were fixed with paraformaldehyde on cover slips. Subcellular localisation was analysed by laser scanning confocal microscope (LSM710; Leica, Wetzlar, Germany) for GFP and endogenous CIC. Nuclei were stained with DAPI $(300 \mathrm{ng} / \mathrm{mL})$. 


\section{Coimmunoprecipitation and immunoblot analysis}

The effect of p.R353X on CIC interaction with KPNA3 and ATXN1 was analysed following previously published protocols. ${ }^{1624}$ Briefly, wildtype or p.R353X mutant GFP-CIC and KPNA3 or ATXN1 plasmid were cotransfected into HEK293T cells. 24 hours post-transfection, the cells were harvested using RIPA lysis buffer. Co-IP and immunoblot GFP antibody was purchased from ThermoFisher (Cat\#A-11120). KPNA3 antibody was purchased from Bethyl Laboratories (Montgomery, Texas, USA).

CIC p.R353X mutant regulation of FOLR1, PCFT, RFC1 gene expression was analysed by immunoblotting assays using FOLR1 antibody (Mov18), PCFT antibody (Abcam) and RFC1 antibody (Santa Cruz Biotechnology) and $\beta$-actin antibody (Cat\# 8-7A5, Developmental Studies Hybridoma Bank at the University of Iowa).

\section{Folic acid (FA) binding assay and FA concentration measurement}

FA binding assay was performed according to previously published methods. ${ }^{7}$ Briefly, HeLa cells stably expressing GFP, GFP-CIC WT or GFP-CIC R353X were exposed for $15 \mathrm{~min}$ to $5 \mathrm{nmol} / \mathrm{L}\left[{ }^{3} \mathrm{H}\right]$ FA (Moravek Biochemicals) in the presence or absence of $500 \mathrm{nmol} / \mathrm{L}$ non-labelled FA. After three ice-cold Hank's balanced salt washes, cell surface bound labelled FA was released with acid buffer and measured on a liquid scintillation spectrometer. Specific FA binding was calculated from the difference between $\left[{ }^{3} \mathrm{H}\right]$ FA bound in the presence and absence of 500 nmol/L non-labelled FA. Stable transfected HeLa cells from an additional well were lysed with $0.2 \mathrm{M} \mathrm{NaOH}$ and protein amount was determined by using the BCA protein kit (Pierce). GFP was used as control. FA concentrations in $\mathrm{H} 9$ stem cell and human iPS cells were measured using FA ELISA kit (BioVision).

\section{Chromatin immunoprecipitation assay}

Chromatin immunoprecipitation (ChIP) was performed following the published protocol of Nelson et al..$^{39}$ Briefly, cells were cross-linked with formaldehyde and then lysed by IP buffer (150 mM NaCl, $50 \mathrm{mM}$ Tris-HCL(PH7.5), $5 \mathrm{mM}$ EDTA, NP-40 $(0.5 \% \mathrm{vol} / \mathrm{vol})$, Triton X-100 (1.0\% vol/vol)). The cell lysis containing nuclear pellets was isolated and sheared using a Misonix Sonicator 4000 (Qsonica LLC, Newtown, CT) by pulsing samples in cold water in a 5.5 inch cup horn 15 times at an amplitude of 60 for $20 \mathrm{~s}$ with $30 \mathrm{~s}$ rests in between pulses. Chromatin samples were separated into two parts, one part incubated with CIC antibody (provided by Dr Huda Zogbhi), and the other part incubated with IgG antibody (Santa Cruz Biotechnology) as a negative control. Protein A beads were used to precipitate the chromatin-protein-antibody complex. ChIP and total DNA were purified using Chelex-100 (Bio-Rad, cat. no. 142-1253) following Nelson and colleagues' protocol. ${ }^{33}$ The purified DNA was subjected to quantitative real-time PCR (qRTPCR), using specific primers for the promoter of the endogenous FOLR1, PCFT, RFC1 genes. The sequences of qRT-PCR primers are provided in online supplementary table.

\section{Luciferase assay}

FOLR1 promoter region containing CIC binding motif(s) were PCR amplified and subcloned into a pGL3-Basic vector. HeLa cells were grown in Dulbecco's Modified Eagle Medium (DMEM) medium supplemented with 10\% FBS and 1\% penicillin \& streptomycin $(\mathrm{P} / \mathrm{S})$ solution. Cells were seeded in 24 -well plates 1 day before transfection. After 24 hours in culture, the cells (70\%-80\% confluence) were transfected with $1 \mu \mathrm{g}$ of GFPCIC plasmids, pGL3 plasmids and 20 ng of the pRL-TK plasmid as internal control with Lipofectamine 2000 (ThermoFisher Scientific). After another 24 hours of culture, the transfected cells were lysed in $0.5 \mathrm{~mL}$ lysis buffer (Promega), incubated on ice for $10 \mathrm{~min}$ and then centrifuged at $5000 \mathrm{rpm}$ for $5 \mathrm{~min}$. The supernatant $(50 \mu \mathrm{L})$ was then assayed for luciferase activity with the Dual-luciferase Reporter Assay using BioTek Synergy HT Multi-Mode Microplate Reader (BioTek Instruments, Winooski, Vermont, USA). Three independent transfection experiments were performed in triplicate for each assay.

\section{Patient fibroblast culture and inducing pluripotent stem cells (iPSC)}

The skin sample was harvested under the guidelines approved by the Institutional Review Board of The University of Texas at Austin and the Seton Family of Hospitals. Fibroblasts from the skin biopsy were cultured in the IMDM (Iscove's Modified Dulbecco's Medium) supplemented with 10\% FBS (Fetal bovine serum) and $1 \% \mathrm{P} / \mathrm{S}$ solution in normal cell culture condition $\left(37^{\circ} \mathrm{C}\right.$ and $\left.5 \% \mathrm{CO}_{2}\right)$ and frozen in liquid nitrogen for preservation. An aliquot containing $10^{5}$ fibroblasts were reprogrammed on the third passage by introducing the four Yamanaka factors $\left(\mathrm{Oct} 4\right.$, Sox2, Kif4, c-Myc) ${ }^{40}$ using CytoTune-iPS 2.0 Sendai Reprogramming Kit (ThermoFisher Scientific) following the protocol guidelines provided by the manufacturer. The medium was changed every 24 hours after transduction for 6 days. On the 7 th day, the cells were harvested using $0.05 \%$ trypsin/ EDTA and plated on dishes with $\gamma$-irradiated mouse embryonic fibroblasts in human embryonic stem cell medium (KO DMEM supplemented with $20 \% \mathrm{KO}$ serum, $2 \mathrm{mM}$ glutamax, $1 \% \mathrm{P} / \mathrm{S}$, $0.1 \mathrm{mM} \beta$-mercaptoethanol, $1 \%$ non-essential amino acids and $10 \mathrm{ng} / \mathrm{mL}$ bFGF (ThermoFisher Scientific). After approximately 14 days, iPSC colonies formed. Four colonies were picked manually and passaged for expansion, karyotyping and freezing. From the third passage, iPSC colonies were transferred to Matrigel coated plates with mTeSR1 medium (Stemcell) to maintain under feeder-free conditions. Karyotyping was performed by WiCell Research Institute in Madison, Wisconsin, USA. The absence of Sendai virus vector in iPSCs was verified by Applied Biosystems TaqMan iPSC Sendai Detection Kit (Applied Biosystems A13640).

\section{FOLR1 autoantibody detection}

The assay for identification of the presence and relative quantification of FOLR1 autoantibodies in serum samples was performed as previously published. ${ }^{41-43}$ Horseradish peroxidase (HRP) labelled anti IgG antibody (Cat\#I8640 Sigma Aldrich) and IgM antibody (Cat\#I8260, Sigma Aldrich) were used to detect IgG and IgM. Antibody-depleted sera (Sigma Aldrich) was used as negative control. Serum effect on blocking FA binding to folate binding protein was detected using HRP labelled FA (FAHRP, Ortho-Clinical Diagnostics, Raritan, New Jersey, USA). FA in serum samples was removed as previously described. ${ }^{44}$ Unlabelled FA was spiked $(0.01-2000 \mathrm{ng} / \mathrm{mL})$ into stripped antibody depleted sera to generate the standard curve. The SuperSignal ELISA Femto Substrate (Cat\#37074, ThermoFisher Scientific) was used as substrate for detection of HRP activity. Images were collected using a 96-well imager (Q-View Imager, Quansys Biosciences). Intensities were extracted from the images using Q-View Software. IgG, IgM and relative FA-blocking amount were calculated based on the standard curves. 


\begin{tabular}{|c|c|c|c|c|c|c|c|}
\hline Sample & Gene & Exonic_Function & AAChange & SIFT & Prediction & PolyPhen2 & Prediction \\
\hline CFD6A & ATP1A1 & Non-synonymous SNV & NM_000701:c.G1579A:p.E527K & 0.04 & D & 0.002 & B \\
\hline CFD7A & SGK223 & Non-synonymous SNV & NM_001080826:c.A308C:p.N103T & 0.01 & $\mathrm{D}$ & 0.003 & B \\
\hline CFD8A & RGPD2 & Startloss SNV & NM_001078170:c.T2C:p.M1T & 1 & 1 & 1 & 1 \\
\hline CFD4A & SLC5A9 & Non-synonymous SNV & NM_001011547:c.A1979G:p.H660R & 0.45 & $\mathrm{~T}$ & 0 & B \\
\hline CFD4A & SLC35A2 & Non-synonymous SNV & NM_001042498:c.G991A:p.V331I & 0 & D & 0.997 & D \\
\hline CFD9A & ABCA12 & Non-synonymous SNV & NM_015657:c.G3539C:p.R1180T & 0 & D & 0.997 & D \\
\hline CFD12A & AKAP12 & Non-synonymous SNV & NM_144497:c.C2957T:p.S986L & 0.25 & $\mathrm{~T}$ & 0 & B \\
\hline CFD1A & $\mathrm{CIC}$ & Stopgain SNV & NM_015125:c.C1057T p.R353X & l & 1 & 1 & 1 \\
\hline
\end{tabular}

AAChange, amino acid change; B, Benign; CFD, cerebral folate deficiency; D, Damaging; SNV, single nucleotide variant; T, Tolerant.

\section{Statistical analysis}

Graphics were performed with Excel (Microsoft Excel, V.16.27). Statistical analysis was performed with R (R Core Team, 2013). Data are presented as mean $\pm S E$ of the mean. All data were analysed using two-tailed t-test.

\section{RESULTS}

\section{De novo variants identified in patients with CFD}

WES was performed on DNA samples from eight CFD family trios. Eight de novo variants (DNVs) were discovered in seven different trios (table 1). Among these DNVs, six were identified as de novo missense mutations, and the other two were identified as start loss and stop gain mutations. Four of the six missense variants were predicted to be damaging using Polyphen or SIFT software. ${ }^{35} 36$ We next examined the function of the genes which have putatively deleterious mutations and found that three (ATP1A1, SLC35A2, ABCA12) of the six genes are associated with an active transport pathway. Among these genes, two have already been linked to neuro-related diseases. Mutations in ATP1A1 gene, which encodes the alpha-1 isoform of the $\mathrm{Na}(+), \mathrm{K}(+)$-ATPase, were previously associated with autosomal dominant axonal Charcot-Marie-Tooth disease type 2DD (CMT2DD; OMIM: 618036) ${ }^{45}$ as well as the hypomagnesemia and intractable seizures associated with severe intellectual disability (HOMGSMR2; OMIM: 618314). ${ }^{46}$ SLC35A2 is known to transport uridine 5-prime-diphosphate-galactose from the cytoplasm to the Golgi. ${ }^{47}$ Mutations in SLC35A2 were associated with early infantile epileptic encephalopathy-22 (EIEE22; OMIM: 300896). ${ }^{48}$ These results suggest that different mutations in known disease-related active transport genes may have different downstream clinical impact on patients.

Among the two putative LoF (loss of function) variants, one locates in the RGPD2 gene (NM_001078170:c.T2C:p. M1T), which encodes a nucleoporin member that has not yet been linked to any known disease. However, other nucleoporin proteins have previously been associated with multiple human diseases, including Down Syndrome and B-ALL. ${ }^{49}$ It is interesting to further explore whether this start loss mutation contributes to the CFD aetiology. The other LoF mutation locates at CIC gene (NM_015125:c.C1057T p.R353X) (figure 1). The patient was
A

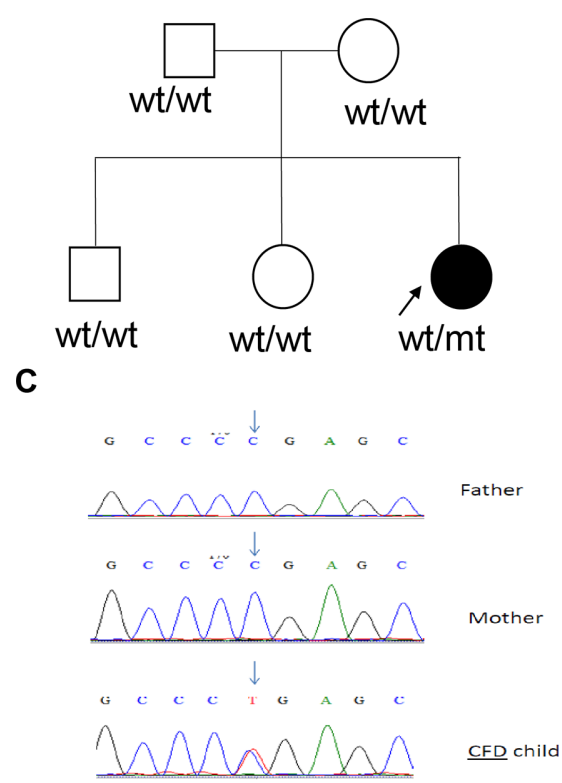

CIC c.1057C>T (p.R353X)
B

Family 2

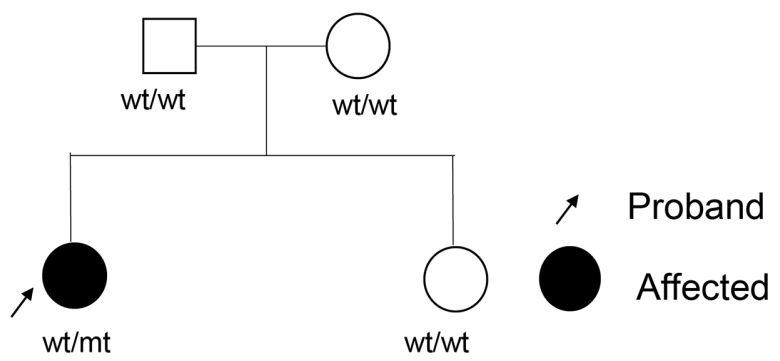

D

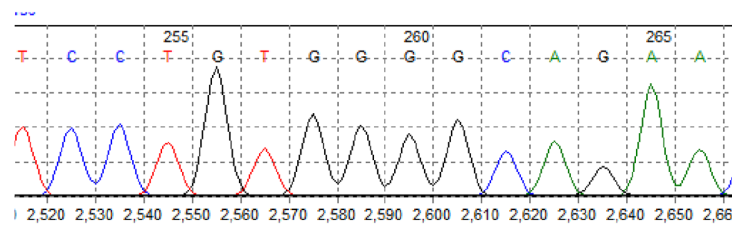

$w t / w t$

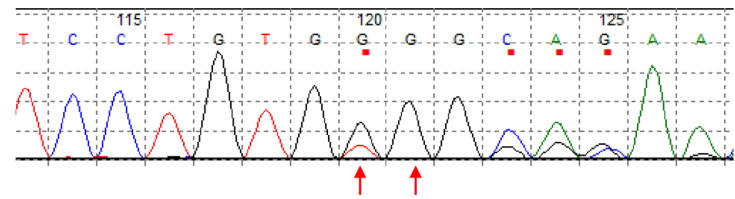

Het

CIC c.1008_1009InsTG

Figure 1 Identification of CIC de novo variants in two CFD sibships. (A) Pedigree of Family 1. (B) Pedigree of Family 2. (C) Sequence chromatogram of Family 1 proband and her parents. (D) Sequence chromatogram of Family 2 proband and the health sibling. CFD, cerebral folate deficiency. 
Table 2 Summary of all CIC rare mutations identified in gnomAD_freq: data from gnomAD database 'allele frequency' (CADD_pred score was calculated from https://cadd.gs.washington.edu/score)

\begin{tabular}{llllll}
\hline Sample & Gene & Exonic_Function & AAChange & gnomAD_freq & CADD_phred \\
\hline CFD-4GS-A & CIC & Non-synonymous SNV & NM_015125:c.C4802T:p.P1601L & $8.29 E-06$ & 23.4 \\
CFD-B36 & CIC & Non-synonymous SNV & NM_015125:c.G1738T:p.G580C & $3.92 E-05$ & 23.9 \\
CFD-1NA & CIC & Stopgain SNV & NM_015125:c.C1057T:p.R353X & 0 & 28.8 \\
CFD-1SG & CIC & Frameshift Insertion & NM_015125:c.1008_1009InsTG:p.G337GfSX40 & 0 & / \\
\hline
\end{tabular}

AAChange, amino acid change.

previously diagnosed to have signs of autistic spectrum disorder, seizures, loss of repetitive language and loss of motor skills. ${ }^{13}$ More recently, she was diagnosed as having features consistent with a CFD diagnosis. Using WES, we determined that this patient lacks rare variants in any known folate transport genes (FOLR1, PCFT and DHFR) (allele frequency $<0.1 \%$ in gnomAD dataset). We also sequenced her healthy siblings' DNA and failed to detect the same mutation. To validate mutations in the CIC gene that potentially contributes to CFD, we performed WES on 48 sporadic patients' DNA. No missense rare variants that were previously identified in reported CFD genes were observed. In contrast, we identified another three patients with rare putatively deleterious mutations (CADD score $>20$ ) in the CIC gene in this cohort (table 2). We contacted these three families and managed to obtain one (CIC c.1008_1009InsTG) of these three mutation carrier's family members' DNA samples and performed following Sanger sequencing on the CIC gene. The frameshift CIC variant (CIC c.1008_1009InsTG) that was identified in the patient with CFD was not detected in the parents and her healthy sibling (figure 1), indicating that this frameshift mutation is another DNM. Compared with the de novo predicted-to-be loss of function $(\mathrm{LoF})$, there is a significant $\left(\mathrm{p}=7.05 \times 10^{-5}\right)$ enrichment of CIC de novo predicted to be LoF variants in patients with CFD. Overall, these data suggest a significant enrichment of CIC mutations in patients with CFD.

\section{Subcellular localisation and protein-protein interaction}

In order to understand the mechanism by which CIC mutations could contribute to developing CFD, functional analyses were performed using the CIC p.R353X truncated variant. Protein domain analysis demonstrated that the CIC p.R353X mutation is predicted to create a stop codon before the C2, NLS1 and C1 domains (figure 2A), which would affect CIC protein nuclear localisation. Subcellular localisation assays indicated that wildtype EGFP-CIC proteins were localised in the nucleus, while the p.R353X mutant EGFP-CIC proteins were widely distributed all over the cells, including the nucleus, cytoplasm and cell membrane, similar to the EGFP protein (figure 2B, online supplementary figure 1). The variant effect on interactions between CIC and KPNA3 or ATXN1 was evaluated by coimmunoprecipitation (Co-IP) assays. In the Co-IP assay, the p.R353X variant abolished CIC interaction with KPNA3 (figure 2C); however, the interaction between mutant CIC (p.R353X) and Ataxin1 was still detectable, although it was weaker than the wildtype CIC interaction with Ataxin1 (figure 2D).
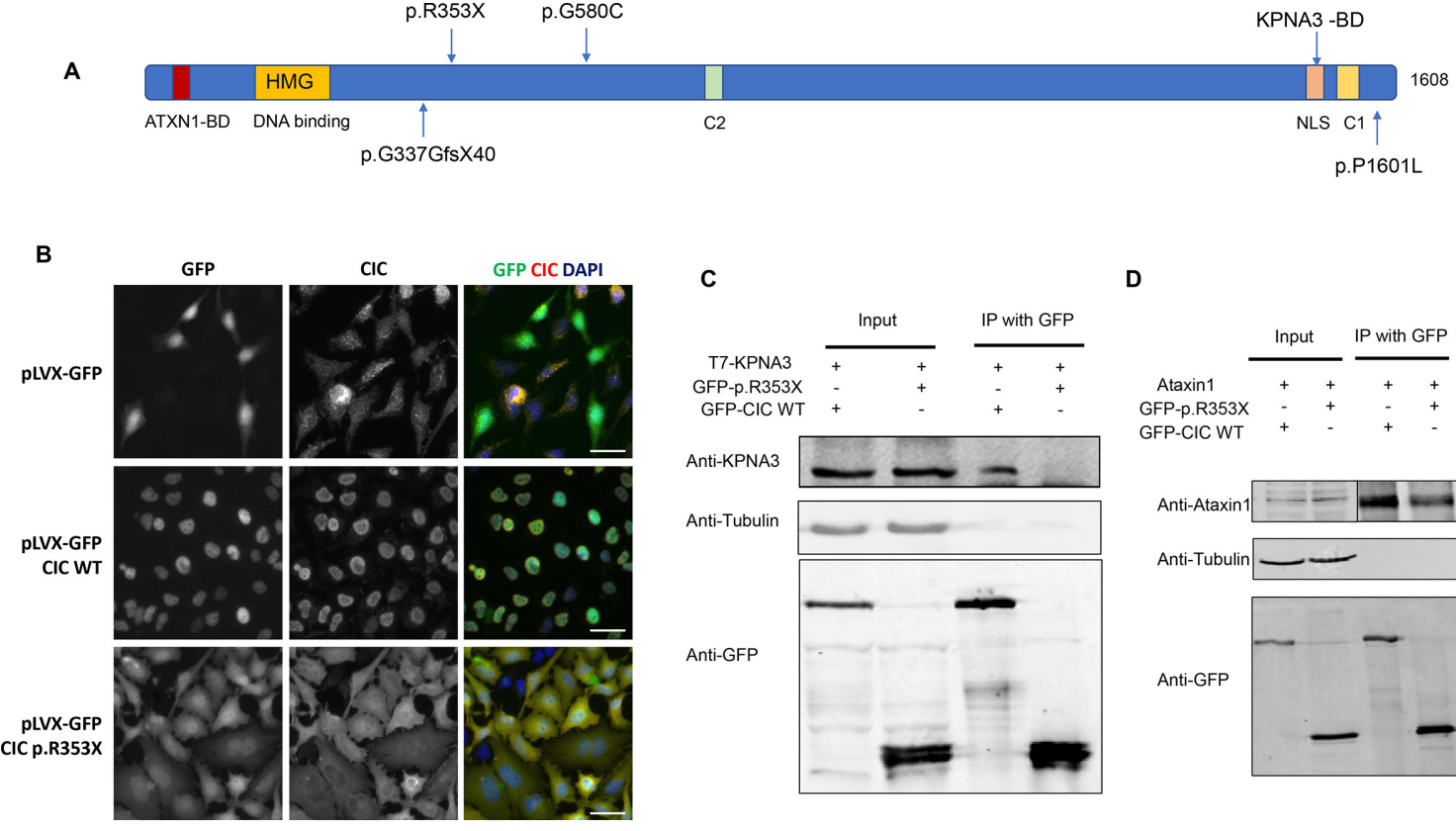

D
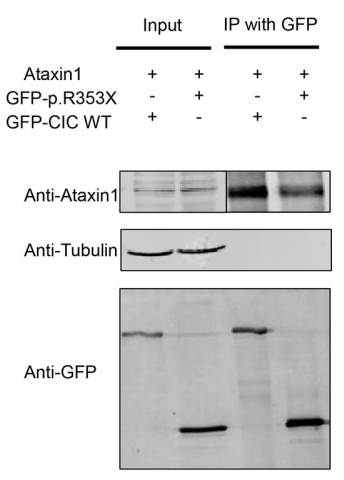

Figure 2 Functional analysis of the CIC variant. (A) Protein amino acid locus of variant p.R353X, which is predicted to create premature stop codons. Lollipop plot shows all four CIC mutants identified in our CFD cohort. ${ }^{56}$ (B) Localisation of GFP tagged CIC variants in stably transfected HeLa cells. HeLa cells were transduced with lentiviral particles coding for GFP, GFP-CIC wildtype or GFP-CIC p.R353X. Subcellular localisation was analysed by microscopy for GFP and endogenous CIC. Nuclei were stained with DAPI, Bars, $20 \mu \mathrm{m}$. (C) Analysis of CIC p.R353X variant effect on interaction between CIC and KPNA3. Mutant CIC abolished interaction between CIC and KPNA3. (D) Analysis of CIC p.R353X variant effect on interaction between CIC and ATXN1. CFD, cerebral folate deficiency. 
A

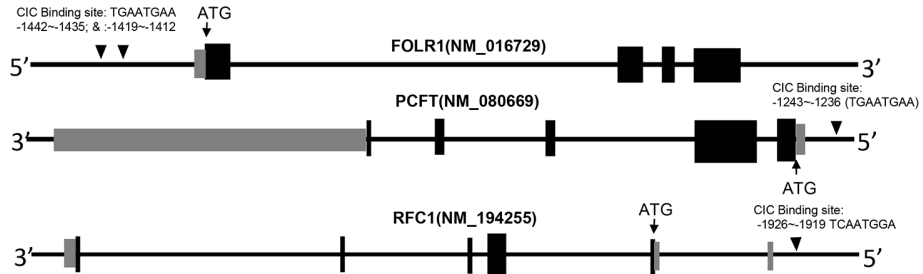

B
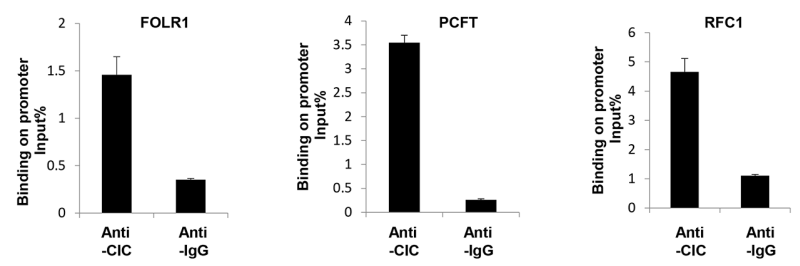

C

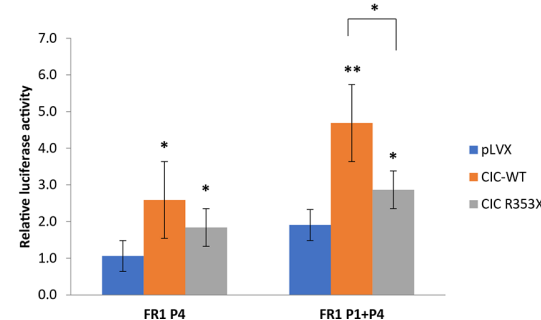

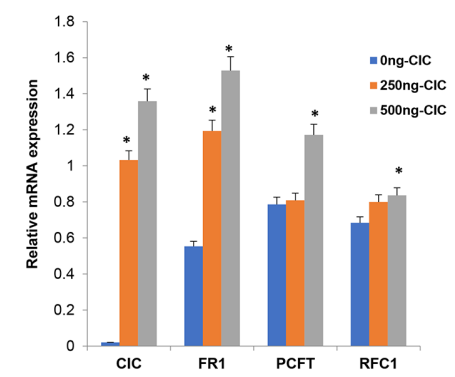

E

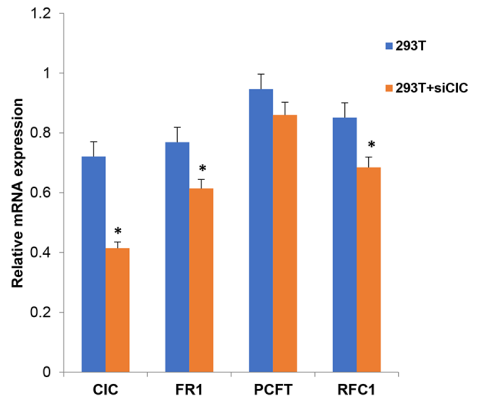

Figure 3 Wildtype CIC regulation of FOLR1, PCFT and RFC1. (A) CIC DNA binding motifs distribution on FOLR1, PCFT and RFC1 gene. FOLR1 has two $\mathrm{CIC}$ binding motifs in promoter region, while PCF and RFC1 have only one CIC binding motif separately. (B) CIC overexpression by transfecting GFP-CIC plasmid and FOLR1, PCFT and RFC1 gene expression detected by qRT-PCR. CIC overexpression significantly increased FOLR1 and PCFT gene expression. (C) Luciferase assay of FOLR1 promoter indicated that wildtype CIC could stimulate FOLR1 promoter-luciferase expression, while mutant CIC had less ability in stimulating FOLR1 promoter-luciferase expression. Student's t-test was performed ( $\left.{ }^{*} p<0.05 ;{ }^{*} p<0.005\right)$. (D) CIC knockdown by anti-CIC siRNA (si-CIC) and the regulation of three folate transport genes, FOLR1, PCFT and RFC1. Student's t-test was performed $\left({ }^{*} p<0.05\right)$. (E) CIC knockdown significantly decreased FOLR1 expression. Student's t-test was performed $\left({ }^{*} \mathrm{p}<0.05\right)$.

\section{$\mathrm{CIC}$ binds to promoter region of FOLR1 and regulates FOLR1 expression}

Examination of the CIC DNA binding octamer sequence in the FOLR1 promoter region, including two thousand base pairs upstream of the transcriptional starting site $(+1)$ indicated that there were two CIC binding sites. One octamer (TGAATGAA) was located at $-1442 \mathrm{bp}$ and the other (TGAATGAA) at -1419 bp (figure $3 \mathrm{~A}$ ). CIC binding octamers were also located in the promoter region of PCFT and RFC1 at $-1243 \sim-1236$ bp and $-1926 \sim-1919 \mathrm{bp}$, respectively (figure 3A). The ChIP assay demonstrated that CIC physically binds to the promoter region of FOLR1, PCFT and RFC1. Compared with IgG control antibody, CIC antibody enriched 4.1-fold more targeted FOLR1 promoter DNA, 13.8-fold more targeted PCFT promoter DNA and 4.2-fold more targeted RFC1 promoter DNA (figure $3 \mathrm{~B}$ ). To determine whether CIC could regulate FOLR1 promoter activity, we cotransfected HeLa cells with two distinct FOLR1 promoter constructs (FR1 P4 or FR1 P1+P4) and either GFPCIC wildtype, GFP-CIC mutant or GFP-pLVX. Both FOLR1 promoter constructs contain the putative CIC binding sites. The luciferase activity was significantly increased for both FOLR1 promoter constructs cotransfected with CIC wildtype (2.6-fold), whereas the effect was much smaller for CIC p.R353X variant (1.5-1.8-fold; figure 3C), suggesting that CIC regulates FOLR1 expression. Upregulating CIC by transfecting $500 \mathrm{ng}$ GFP-CIC wildtype plasmid into HEK293T cells increased FOLR1, PCFT and RFC1 gene expression by 2.8 -fold, 1.5 -fold and 1.2 -fold, respectively (figure 3D). Downregulating 43\% of CIC expression by siRNA transfection significantly reduced FOLR1 and RFC1 expression by 20\% (figure 3E).

\section{CIC variant downregulated FOLR1 expression in cell lines}

To determine whether the p.R353X variant could affect expression of folate transport genes, we generated stable HeLa and Caco-2 cell lines expressing GFP, GFP-CIC wildtype and GFPCIC p.R353X.

In HeLa cells, both western blotting and qRT-PCR assays demonstrated that wildtype GFP-CIC increased FOLR1 expression by $2.2 \times$ fold $(\mathrm{p}<0.01)$ compared with GFP controls, while mutant GFP-CIC decreased FOLR1 expression by $51 \%$ $(\mathrm{p}<0.05)$ compared with GFP controls. PCFT and RFC1 expression was not significantly $(\mathrm{p}>0.05)$ altered in the transfected cells (figure $4 \mathrm{~A}-\mathrm{C}$ ). The effect of $\mathrm{CIC}$ variant downregulation on FOLR1 expression in comparison to CIC wildtype was confirmed in Caco-2 cells (figure 4D-F).

\section{CIC variants downregulated FOLR1 expression in patient iPSCs}

To determine whether the CIC variant downregulated FOLR1 expression in patient cells, we collected fibroblast cells from the original CFD proband and generated iPSCs. Sanger sequencing indicated that both a wildtype and a mutant copy of the CIC gene was observed (figure 5A), suggesting that nonsense mediated decay failed to remove all of the mutant mRNAs. qRT-PCR assays demonstrated that the CIC variant downregulated FOLR1 gene expression by $47 \%$ in the proband iPSC compared with control iPSCs (figure 5B). Immunoblotting assay indicated that CIC variant downregulated FOLR protein expression by $37 \%$ in the iPSCs comparison (figure 5C,D). PCFT and RFC1 were also downregulated by $44 \%$ and $51 \%$, respectively, in their mRNA 

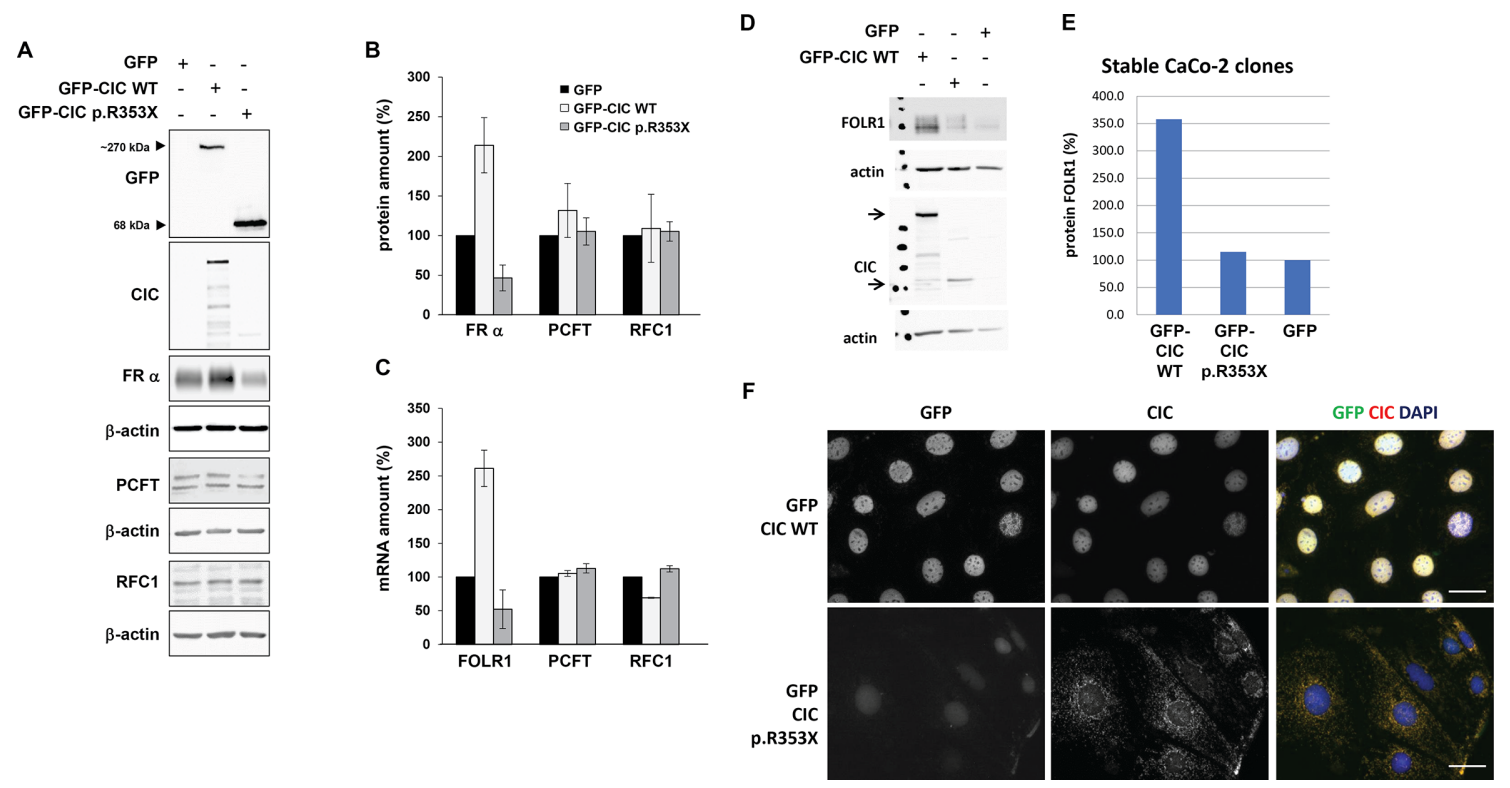

Figure 4 Wildtype and mutant $\mathrm{CIC}$ regulated the transcription of FOLR1 in stably transfected HeLa cells. (A) HeLa cells were transduced with lentiviral particles coding for GFP, GFP-CIC wildtype or GFP-CIC p.R353X. Representative western blots of endogenous FOLR1 (FR $\alpha$ ), PCFT and RFC1 and overexpressed GFP-CIC. $\beta$-actin was used as a loading control. (B) Protein quantification of FOLR1, PCFT and RFC1 relative to GFP transfected HeLa cells (normalised against $\beta$-actin, $n=3$ ). (C) Quantification of FOLR1, PCFT and RFC1 mRNA levels in HeLa cells, stably transfected with GFP, GFP-CIC WT or GFP$\mathrm{CIC}$ p.R353X. Expression was normalised against GAPDH ( $n=3$ ). (D) Caco-2 cells were transduced with lentiviral particles coding for GFP, GFP-CIC wildtype or GFP-CIC p.R353X. Representative western blots of CIC and endogenous FOLR1 expression. B-actin was used as loading control. (E) Protein quantification of FOLR1 relative to GFP transfected Caco-2. (F) Protein localisation of wildtype and mutant type GFP-CIC in Caco-2 cells. Bars, $10 \mu \mathrm{m}$.

A

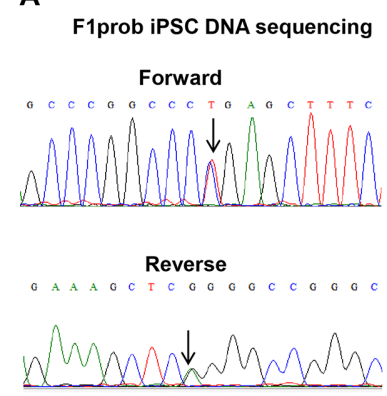

C

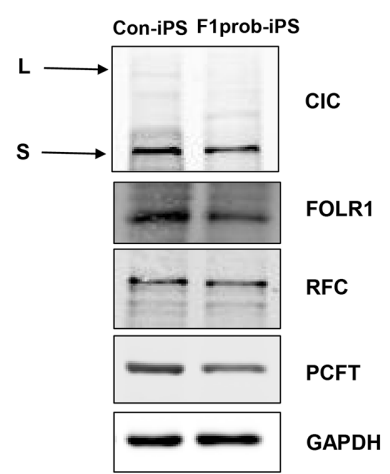

F1prob iPSC cDNA sequencing Forward
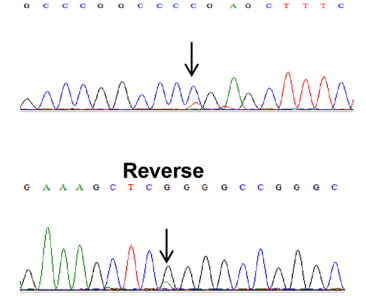

B

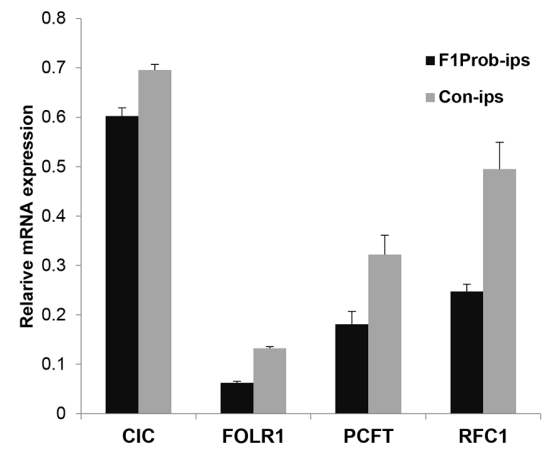

Figure 5 Family 1 proband iPSC's CIC expression and its regulation on folate transporters. (A) Family 1 proband (F1prob) iPS cell DNA sequencing and CDNA sequencing chromatogram indicated that mutant CIC mRNA was less than wildtype CIC mRNA. (B) qRT-PCR analysis of CIC, FOLR1, PCFT and RFC1 in family 1 proband iPSCs and control iPSCs. (C) Immunoblotting analysis of CIC, FOLR1, PCFT and RFC1 protein expression in F1prob iPSCs and control iPSCs. (D) Quantification of immunoblotting using ImageJ, GAPDH protein amount was used as reference. 
A

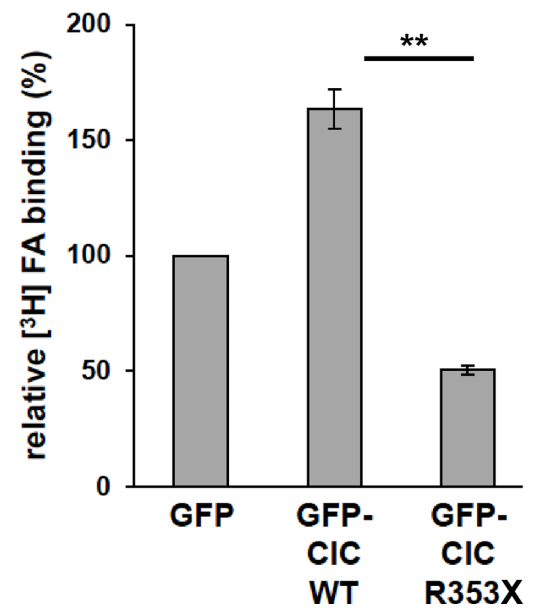

B

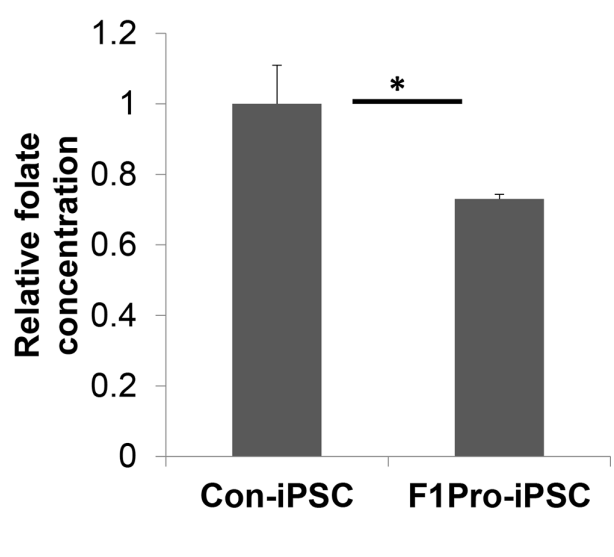

Figure 6 Effect of $\mathrm{ClC}$ variants on binding of folic acid and cellular folate concentration. (A) Folic acid surface binding by HeLa cells stably expressing GFP, GFP-CIC WT or GFP-CIC p.R353X. Cells were exposed to $5 \mathrm{nmol} / / \mathrm{L}\left[{ }^{3} \mathrm{H}\right.$ ] folic acid binding was calculated relative to GFP transfected cells ( $\mathrm{n} \geq 3$, each carried out in duplicate), ${ }^{* *} \mathrm{p}<0.01$. (B) Folate concentration in control iPSCs and family 1 proband iPSCs, ${ }^{*} p<0.05$.

levels (figure 5B) and by $35 \%$ and $33 \%$ in their protein concentrations (figure $5 \mathrm{C}, \mathrm{D}$ ).

\section{Folic acid binding assay}

The FA surface binding activity of HeLa cells stably expressing GFP, GFP-CIC WT or GFP-CIC p.R353X was determined (figure 6A). As expected, the CIC p.R353X variant reduced HeLa cells ability to bind FA by twofold $(\mathrm{p}<0.01)$ compared with wildtype GFP-CIC. The concentration of folate in iPSCs derived from the patient was also determined (figure 6B). Folate concentration was decreased by $25 \%(\mathrm{p}<0.05)$ in iPSCs derived from the CIC p.R353X variant carrier when compared with iPSCs derived from a control donor lacking the CIC LoF variant (figure 6B).

\section{FOLR1 autoantibody analysis}

Multiple serum samples were collected from the patient with CFD and tested using the previously described microELISA assays for the detection of autoantibodies to FOLR1 and inhibition of FA binding to FOLR1. ${ }^{41}$ All samples tested positive for
IgG autoantibodies to FOLR1, but the relative concentration of IgG was variable (patient range 1.7-52.2) over time (days 1, 8, 15, 22, 64, 131, 134, 236 and 293) (figure 7A). The blocking of FA uptake and binding by patient serum was also variable $(0.63-1.77 \mathrm{ng} / \mathrm{mL})$ over the same timepoints (figure $7 \mathrm{~B})$. The concentration of IgG levels was not correlated with the serum blocking of FA binding to FOLR1 (Pearson $r=0.03, p=0.94$ ).

\section{DISCUSSION}

In this study, we did the first trio-based genetic analysis on patients with CFD and identified mutations in CIC genes that may play important roles in determining CFD risk. Using functional biochemistry assays, we were able to demonstrate a novel genetic aetiology of CFD, which we believe is mediated through regulating FOLR1 gene expression secondary to mutations in CIC. Previous studies indicated that the DNA variants in the folate receptor (ie, FOLR1), folate transporter (ie, PCFT) and genes involved in folate metabolism (ie, DHFR) can influence folate uptake and produce the CFD phenotype. We have now identified a gene that is not directly involved in folate uptake

\section{A}

B
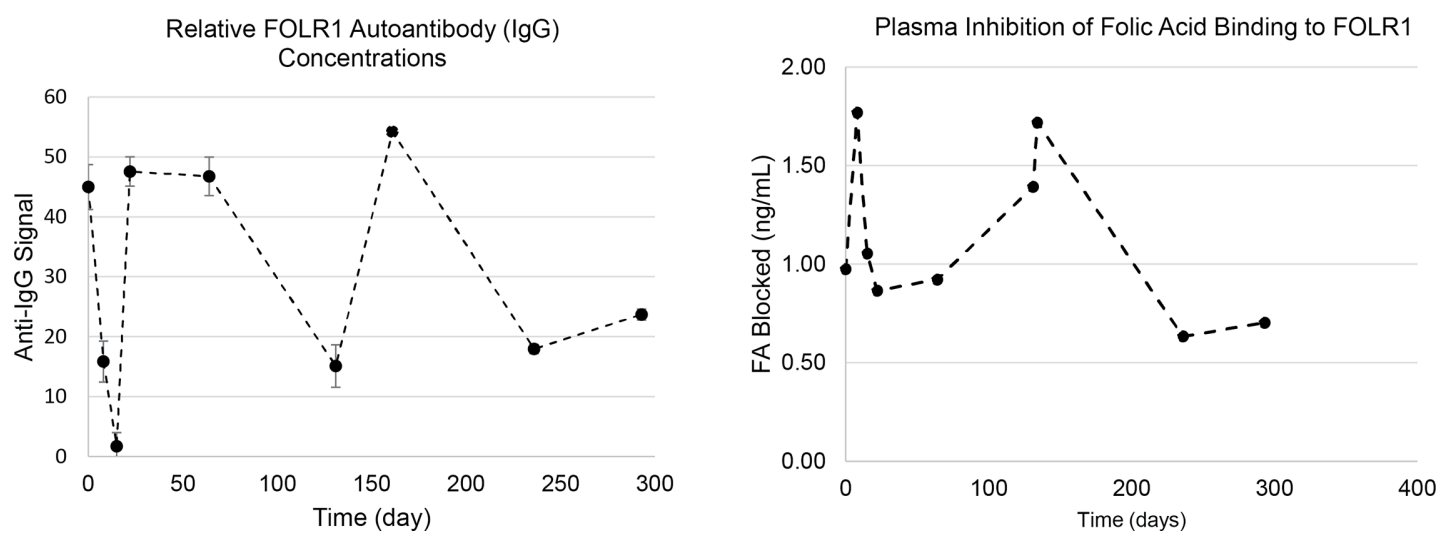

Figure 7 Family 1 proband serum FOLR1 autoantibody measurements in 2005. (A) IgG FOLR1 autoantibody measurement during 2005. (B) FA blocking autoantibody measured in 300 days. Both autoantibody concentration and blocking of FA binding were fluctuating throughout the measurement time points. 
or metabolism yet contributes to the development of CFD. Active transport genes were known to be highly associated with genetic diseases, while the CIC gene is not directly involved in any uptake or transport pathway, yet it can contribute to the development of CFD through the regulation of FOLR1 and other genes involved in choroid plexus epithelial folate uptake. Several potential mechanisms could contribute to the lower expression of FOLR1 caused by the CIC mutant. CIC variants could prevent CIC nuclear localisation. Second, CIC variants could affect CIC's DNA binding ability and inefficient promoter transcription as demonstrated by the luciferase assay (figure 3 ). Another possible scenario involves the malfunctioning mutant CIC protein binding to FOLR1 promoter to prevent wildtype CIC from binding to DNA, although this is less likely the case for CIC p.R353X, as the nuclear translocation of mutant CIC is impaired by the variant.

The difference between the CIC variant associated with CFD and FOLR1 mutations that have been previously reported to cause CFD is that the FOLR1 mutations were reported to produce a very severe CFD (CSF $5-\mathrm{MTHF}<5 \mathrm{nmol}$ ) phenotype, while the deleterious mutations in $\mathrm{CIC}$ had a more mild impact (CSF 5-MTHF: 20-30 nmol). The possibility that other genes, including other transcription factors, and cellular interactions indirectly related to folate uptake and metabolism can increase the risk of CFD, suggests that the underlying aetiologies of CFD includes secondary or tertiary modifiers of folate uptake, and that these may result in less severe phenotypes.

Since the initial discovery of CIC in 2000, scientists have continued to learn the extent of CIC's involvement in many diverse cellular pathways, including impact on proliferation, cancer initiation, tumour development and metastasis. ${ }^{50}$ The observation that CIC binds to the promoter region of FOLR1 indicates a new function for CIC, that is, the regulation of FOLR1 gene expression and regulation of genes related to folate uptake and metabolism. It is well established that CIC is a transcriptional repressor. ${ }^{14}$ In this study, we demonstrated that CIC functioned as a transcription activator of FOLR1. Increased amounts of CIC protein promoted FOLR1 expression, while decreased CIC expression resulting from siRNA silencing reduced FOLR1 gene expression. The change in gene expression was also found in protein levels, and by regulating the amount of FOLR1 available, CIC is expected to thereby modify CSF folate concentrations. To date, several early developmental phenotypes, such as lung alveolarisation, omphalocele and gut malformations observed in germline Cic $\mathrm{KO}$ mice have not been previously associated with CIC variants in human studies. These phenotypes may also be influenced by folate availability, similar to CFD, so we propose searching for CIC variants in human subjects with comparable malformations and attempt to prevent the recurrence of these malformations in CIC mutant embryos via maternal folate supplementation.

It was previously reported that high titres of FOLR1 autoantibody are associated with the CFD phenotype and can functionally block the ability of FOLR1 to bind and transport folates. ${ }^{8}$ CIC deficiency was previously reported to promote $\mathrm{T}$ cell differentiation and induce autoimmunity, ${ }^{26}$ so we expected to detect FOLR1 autoantibody in the CIC p.R353X carrier. However, we observed that the serum FOLR1 autoantibody levels varied at different time points. This result is consistent with an earlier report by Ramaekers and coworkers on the variable levels of FOLR1 autoantibodies over time. ${ }^{51}$ Autoantibodies to FOLR1 were also reported to respond to folate supplementation, so folate serum concentrations may be a modifier of FOLR1 autoantibodies and FOLR1 expression. ${ }^{5253}$
It has also been reported that folate supplementation results in a loss of significant correlations between folate, homocysteine and autoantibodies concentrations. ${ }^{53}$ The lack of correlation between autoantibodies in this patient and serum blocking of FOLR1-folate binding indicates that autoantibodies, serum and CFD folate concentrations may vary over time and thereby influence day to day physiology, such that the impact of FOLR1 and CIC on CFD should be examined on more than one occasion in order to avoid detection of spurious depressed or elevated readings. A large CFD-control cohort with multiple sampling time points for folate, CSF folate, and FOLR1 autoantibody data are required to best determine whether CIC deficiency also increases the risk of FOLR1 autoantibodies and thereby also contributes to CFD risk.

Current studies on CIC molecular interactions are not sufficient to provide explanations for the range of phenotypic variations that were observed among patients carrying different CIC LoF variants. We previously reported five patients with CIC mutations, whose most consistent clinical features were development delay and intellectual disability, as all five patients shared these characteristics. ${ }^{13}$ The other documented phenotypes were only present in a portion of the CIC truncating mutation carriers. The initial patient with CFD (p.R353X carrier) had B-cell ALL and was treated with MTX for 2 years, while the second patient with CFD (p.1008_1009InsTG carrier) identified in the validation studies, did not present with any cancer pathology. No CSF samples were available from the other four CIC LoF variants carriers described in our previous paper, ${ }^{13}$ so we do not know whether they also had low folate CSF concentrations. The different phenotypes observed among different CIC LoF carriers may be due to a combination of different factors, including genetic background and ability to uptake folate, as well as different environmental exposures. We checked GeneMatcher ${ }^{54}$ data and found $16 \mathrm{LoF}$ CIC variants records. Based on previous CFD studies, ${ }^{55}$ it may be helpful for medical researchers and clinical care providers of CIC carrier patients to examine tissue folate levels and consider examination of folate supplementation in patients, especially if 5-MTHF concentrations are significantly lower than the normal range in serum or CSF.

\section{Author affiliations}

${ }^{1}$ Center for Precision Environmental Health, Department of Molecular and Cellular Biology, Baylor College of Medicine, Houston, Texas, USA

${ }^{2}$ Department of Pediatric Neurology, University Medical Center Göttingen, Gottingen, Niedersachsen, Germany

${ }^{3}$ Department of Pediatrics, University of Texas at Austin, Austin, Texas, USA

${ }^{4}$ Department of Nutritional Sciences, University of Texas at Austin Dell Medical School, Austin, Texas, USA

${ }^{5}$ Institute for Cell and Molecular Biology, The University of Texas at Austin, Austin, Texas, United States

${ }^{6}$ Department of Pediatric Neurology, University Hospital Center Liège, Liège, Belgium ${ }^{7}$ University Children's Hospital Zurich, Zurich, Switzerland

${ }^{8}$ Center for Precision Environmental Health, Departments of Molecular and Cellular Biology and Medicine, Houston, Texas, USA

${ }^{9}$ Departments of Molecular and Human Genetics and Medicine, Baylor College of Medicine, Houston, Texas, United States

Acknowledgements We thank the families for their participation in the study. Dr Huda Zoghbi (Baylor College of Medicine) for providing anti-CIC antibody and Dr Carol Mackintosh (University of Dundee) for providing HA-KPNA3 plasmid. The authors acknowledge the Texas Advanced Computing Center (TACC) at The University of Texas at Austin for providing High Performance Computing (HPC) resources that have contributed to the research results reported within this paper. URL: http://www.tacc.utexas.edu.

Contributors $Y L, A W, S-E K, R S$ and RHF conceived and designed the experiments. RC performed FOLR1 autoantibody detection assay and patient fibroblast cell culture. BW provided critical input to the project. XC and $\mathrm{HZ}$ assisted in the genetic analysis 
of the whole-exome sequencing data. MP performed human iPSCs generation. IS performed qRT-PCR. XH performed overexpression and co-IP assays. RHF, RS, XC and $Y L$ recruited patients, acquired clinical data or analysed whole exome sequencing or Sanger sequencing results. YL, XC, RC, AW, S-EK, RS and RHF drafted the original manuscript and all authors assisted in editing the manuscript.

Funding This project was supported in part by grants NIH R01 HD081216 and HD083809 to RHF.

\section{Competing interests None declared.}

Patient consent for publication Not required.

Provenance and peer review Not commissioned; externally peer reviewed.

Data availability statement Data are available on reasonable request. Data are available from the corresponding author on request.

Open access This is an open access article distributed in accordance with the Creative Commons Attribution Non Commercial (CC BY-NC 4.0) license, which permits others to distribute, remix, adapt, build upon this work non-commercially, and license their derivative works on different terms, provided the original work is properly cited, appropriate credit is given, any changes made indicated, and the use is non-commercial. See: http://creativecommons.org/licenses/by-nc/4.0/.

\section{ORCID iDs}

Vincent Th Ramaekers http://orcid.org/0000-0003-1076-762X

Yunping Lei http://orcid.org/0000-0003-1504-0884

\section{REFERENCES}

1 Ramaekers VT, Blau N, deficiency Cfolate. Cerebral folate deficiency. Dev Med Child Neurol 2004:46:843-51.

2 Mangold S, Blau N, Opladen T, Steinfeld R, Wessling B, Zerres K, Häusler M. Cerebral folate deficiency: a neurometabolic syndrome? Mol Genet Metab 2011;104:369-72.

3 Said HM. Intestinal absorption of water-soluble vitamins in health and disease. Biochem J 2011;437:357-72.

4 Grapp M, Wrede A, Schweizer M, Hüwel S, Galla H-J, Snaidero N, Simons M, Bückers J, Low PS, Urlaub H, Gärtner J, Steinfeld R. Choroid plexus transcytosis and exosome shuttling deliver folate into brain parenchyma. Nat Commun 2013:4:2123.

5 Chen C, Ke J, Zhou XE, Yi W, Brunzelle JS, Li J, Yong E-L, Xu HE, Melcher K. Structural basis for molecular recognition of folic acid by folate receptors. Nature 2013:500:486-9

6 Steinfeld R, Grapp M, Kraetzner R, Dreha-Kulaczewski S, Helms G, Dechent P, Wevers $R$, Grosso S, Gärtner J. Folate receptor alpha defect causes cerebral folate transport deficiency: a treatable neurodegenerative disorder associated with disturbed myelin metabolism. Am J Hum Genet 2009;85:354-63.

7 Grapp M, Just IA, Linnankivi T, Wolf P, Lücke T, Häusler M, Gärtner J, Steinfeld R. Molecular characterization of folate receptor 1 mutations delineates cerebral folate transport deficiency. Brain 2012;135:2022-31.

8 Ramaekers VT, Rothenberg SP, Sequeira JM, Opladen T, Blau N, Quadros EV, Selhub J. Autoantibodies to folate receptors in the cerebral folate deficiency syndrome. $N$ Engl J Med 2005;352:1985-91.

9 Banka S, Blom HJ, Walter J, Aziz M, Urquhart J, Clouthier CM, Rice GI, de Brouwer APM, Hilton E, Vassallo G, Will A, Smith DEC, Smulders YM, Wevers RA, Steinfeld $R$, Heales $S$, Crow YJ, Pelletier JN, Jones S, Newman WG. Identification and characterization of an inborn error of metabolism caused by dihydrofolate reductase deficiency. Am J Hum Genet 2011;88:216-25.

10 Cario H, Smith DEC, Blom H, Blau N, Bode H, Holzmann K, Pannicke U, Hopfner K-P, Rump E-M, Ayric Z, Kohne E, Debatin K-M, Smulders Y, Schwarz K. Dihydrofolate reductase deficiency due to a homozygous DHFR mutation causes megaloblastic anemia and cerebral folate deficiency leading to severe neurologic disease. Am J Hum Genet 2011;88:226-31.

11 Qiu A, Jansen M, Sakaris A, Min SH, Chattopadhyay S, Tsai E, Sandoval C, Zhao R, Akabas MH, Goldman ID. Identification of an intestinal folate transporter and the molecular basis for hereditary folate malabsorption. Cell 2006;127:917-28.

12 Wang Q, Li X, Ding Y, Liu Y, Qin Y, Yang Y. The first Chinese case report of hereditary folate malabsorption with a novel mutation on SLC46A1. Brain Dev 2015;37:163-7.

13 Lu H-C, Tan Q, Rousseaux MWC, Wang W, Kim J-Y, Richman R, Wan Y-W, Yeh S-Y, Patel JM, Liu X, Lin T, Lee Y, Fryer JD, Han J, Chahrour M, Finnell RH, Lei Y, ZuritaJimenez ME, Ahimaz P, Anyane-Yeboa K, Van Maldergem L, Lehalle D, Jean-Marcais N Mosca-Boidron A-L, Thevenon J, Cousin MA, Bro DE, Lanpher BC, Klee EW, Alexander N, Bainbridge MN, Orr HT, Sillitoe RV, Ljungberg MC, Liu Z, Schaaf CP, Zoghbi HY. Disruption of the ATXN1-CIC complex causes a spectrum of neurobehavioral phenotypes in mice and humans. Nat Genet 2017;49:527-36.

14 Jiménez G, Guichet A, Ephrussi A, Casanova J. Relief of gene repression by torso RTK signaling: role of capicua in Drosophila terminal and dorsoventral patterning. Genes Dev 2000;14:224-31.

15 Ajuria L, Nieva C, Winkler C, Kuo D, Samper N, Andreu MJ, Helman A, GonzálezCrespo S, Paroush Ze'ev, Courey AJ, Jiménez G. Capicua DNA-binding sites are General response elements for RTK signaling in Drosophila. Development 2011;138:915-24.

16 Dissanayake K, Toth R, Blakey J, Olsson O, Campbell DG, Prescott AR, MacKintosh C. ERK/p90(RSK)/14-3-3 signalling has an impact on expression of PEA3 Ets transcription factors via the transcriptional repressor capicúa. Biochem J 2011:433:515-25.

17 Papagianni A, Forés M, Shao W, He S, Koenecke N, Andreu MJ, Samper N, Paroush Ze'ev, González-Crespo S, Zeitlinger J, Jiménez G. Capicua controls Toll/ IL-1 signaling targets independently of RTK regulation. Proc Natl Acad Sci U S A 2018;115:1807-12.

18 Lee Y, Fryer JD, Kang H, Crespo-Barreto J, Bowman AB, Gao Y, Kahle JJ, Hong JS, Kheradmand F, Orr HT, Finegold MJ, Zoghbi HY. Atxn1 protein family and $\mathrm{CIC}$ regulate extracellular matrix remodeling and lung alveolarization. Dev Cell 2011;21:746-57.

19 Okimoto RA, Breitenbuecher F, Olivas VR, Wu W, Gini B, Hofree M, Asthana S, Hrustanovic G, Flanagan J, Tulpule A, Blakely CM, Haringsma HJ, Simmons AD, Gowen K, Suh J, Miller VA, Ali S, Schuler M, Bivona TG. Inactivation of Capicua drives cancer metastasis. Nat Genet 2017:49:87-96.

20 Jiménez G, Shvartsman SY, Paroush Ze'ev. The Capicua repressor--a general sensor of RTK signaling in development and disease. I Cell Sci 2012;125:1383-91.

21 Astigarraga S, Grossman R, Díaz-Delfín J, Caelles C, Paroush Ze'ev, Jiménez G. A MAPK docking site is critical for downregulation of Capicua by torso and EGFR RTK signaling. Embo J 2007;26:668-77.

22 Tseng A-SK, Tapon N, Kanda H, Cigizoglu S, Edelmann L, Pellock B, White K, Hariharan IK. Capicua regulates cell proliferation downstream of the receptor tyrosine kinase/ras signaling pathway. Curr Biol 2007;17:728-33.

23 Jin Y, Ha N, Forés M, Xiang J, Gläßer C, Maldera J, Jiménez G, Edgar BA. EGFR/Ras signaling controls Drosophila intestinal stem cell proliferation via Capicua-Regulated genes. PLoS Genet 2015;11:e1005634.

24 Lam YC, Bowman AB, Jafar-Nejad P, Lim J, Richman R, Fryer JD, Hyun ED, Duvick LA, Orr HT, Botas J, Zoghbi HY. Ataxin-1 interacts with the repressor Capicua in its native complex to cause SCA1 neuropathology. Cell 2006;127:1335-47.

25 Simón-Carrasco L, Graña O, Salmón M, Jacob HKC, Gutierrez A, Jiménez G, Drosten M, Barbacid M. Inactivation of Capicua in adult mice causes T-cell lymphoblastic lymphoma. Genes Dev 2017:31:1456-68.

26 Park S, Lee S, Lee C-G, Park GY, Hong H, Lee J-S, Kim YM, Lee SB, Hwang D, Choi YS, Fryer JD, Im S-H, Lee S-W, Lee Y. Capicua deficiency induces autoimmunity and promotes follicular helper T cell differentiation via derepression of ETV5. Nat Commun 2017:8:16037

27 Bettegowda C, Agrawal N, Jiao Y, Sausen M, Wood LD, Hruban RH, Rodriguez FJ, Cahill DP, McLendon R, Riggins G, Velculescu VE, Oba-Shinjo SM, Marie SKN, Vogelstein B, Bigner D, Yan H, Papadopoulos N, Kinzler KW. Mutations in CIC and FUBP1 contribute to human oligodendroglioma. Science 2011;333:1453-5.

28 Choi N, Park J, Lee J-S, Yoe J, Park GY, Kim E, Jeon H, Cho YM, Roh T-Y, Lee Y. miR93/miR-106b/miR-375-CIC-CRABP1: a novel regulatory axis in prostate cancer progression. Oncotarget 2015;6:23533-47.

29 Li H, Durbin R. Fast and accurate short read alignment with Burrows-Wheeler transform. Bioinformatics 2009;25:1754-60

30 Li H, Handsaker B, Wysoker A, Fennell T, Ruan J, Homer N, Marth G, Abecasis G, Durbin R, 1000 Genome Project Data Processing Subgroup. The sequence Alignment/Map format and SAMtools. Bioinformatics 2009;25:2078-9.

31 McKenna A, Hanna M, Banks E, Sivachenko A, Cibulskis K, Kernytsky A, Garimella K, Altshuler D, Gabriel S, Daly M, DePristo MA. The genome analysis toolkit: a MapReduce framework for analyzing next-generation DNA sequencing data. Genome Res 2010:20:1297-303.

32 Wei Q, Zhan X, Zhong X, Liu Y, Han Y, Chen W, Li B. A Bayesian framework for de novo mutation calling in parents-offspring trios. Bioinformatics 2015;31:1375-81.

33 Wang K, Li M, Hakonarson H. ANNOVAR: functional annotation of genetic variants from high-throughput sequencing data. Nucleic Acids Res 2010;38:e164.

34 Lei Y, Fathe K, McCartney D, Zhu H, Yang W, Ross ME, Shaw GM, Finnell RH. Rare LRP6 variants identified in spina bifida patients. Hum Mutat 2015;36:342-9.

35 Adzhubei I, Jordan DM, Sunyaev SR. Predicting functional effect of human missense mutations using PolyPhen-2. Curr Protoc Hum Genet 2013:Chapter 7:7.20.1-7.20.41.

$36 \mathrm{Ng}$ PC, Henikoff S. Predicting deleterious amino acid substitutions. Genome Res 2001:11:863-74.

37 Rentzsch P, Witten D, Cooper GM, Shendure J, Kircher M. Cadd: predicting the deleteriousness of variants throughout the human genome. Nucleic Acids Res 2019;47:D886-94.

38 Karczewski KJ, Francioli LC, Tiao G, Cummings BB, Alföldi J, Wang Q, Collins RL, Laricchia KM, Ganna A, Birnbaum DP. Variation across 141,456 human exomes and genomes reveals the spectrum of loss-of-function intolerance across human proteincoding genes. BioRxiv 2019;531210.

39 Nelson JD, Denisenko O, Bomsztyk K. Protocol for the fast chromatin immunoprecipitation (CHIP) method. Nat Protoc 2006;1:179-85.

40 Takahashi K, Tanabe K, Ohnuki M, Narita M, Ichisaka T, Tomoda K, Yamanaka S. Induction of pluripotent stem cells from adult human fibroblasts by defined factors. Cell 2007;131:861-72. 
41 Cabrera RM, Shaw GM, Ballard JL, Carmichael SL, Yang W, Lammer EJ, Finnell RH. Autoantibodies to folate receptor during pregnancy and neural tube defect risk. J Reprod Immunol 2008;79:85-92.

42 Yang N, Wang L, Finnell RH, Li Z, Jin L, Zhang L, Cabrera RM, Ye R, Ren A. Levels of folate receptor autoantibodies in maternal and cord blood and risk of neural tube defects in a Chinese population. Birth Defects Res A Clin Mol Teratol 2016;106:685-95.

43 Dong Y, Wang L, Lei Y, Yang N, Cabrera RM, Finnell RH, Ren A. Gene variants in the folate pathway are associated with increased levels of folate receptor autoantibodies. Birth Defects Res 2018;110:973-81.

44 Zettner A, Duly PE. Relative efficacy of separation of "free" and "bound" (3',5'$3 \mathrm{H})$ pteroylglutamate by charcoal coated with various materials. Clin Chem 1975:21:1927-31.

45 Lassuthova P, Rebelo AP, Ravenscroft G, Lamont PJ, Davis MR, Manganelli F, Feely SM, Bacon C, Brožková Dana Šafka, Haberlova J, Mazanec R, Tao F, Saghira C, Abreu L, Courel S, Powell E, Buglo E, Bis DM, Baxter MF, Ong RW, Marns L, Lee Y-C, Bai Y, Isom DG, Barro-Soria R, Chung KW, Scherer SS, Larsson HP, Laing NG, Choi B-O, Seeman P, Shy ME, Santoro L, Zuchner S. Mutations in atp1a1 cause dominant Charcot-MarieTooth type 2. Am J Hum Genet 2018;102:505-14.

46 Schlingmann KP, Bandulik S, Mammen C, Tarailo-Graovac M, Holm R, Baumann M, König J, Lee JJY, Drögemöller B, Imminger K, Beck BB, Altmüller J, Thiele H, Waldegger S, Van't Hoff W, Kleta R, Warth R, van Karnebeek CDM, Vilsen B, Bockenhauer D, Konrad M. Germline de novo mutations in atp1a1 cause renal hypomagnesemia, refractory seizures, and intellectual disability. Am J Hum Genet 2018;103:808-16.

47 Carette JE, Guimaraes CP, Varadarajan M, Park AS, Wuethrich I, Godarova A, Kotecki M, Cochran BH, Spooner E, Ploegh HL, Brummelkamp TR. Haploid genetic screens in human cells identify host factors used by pathogens. Science 2009;326:1231-5.
48 Kodera H, Nakamura K, Osaka H, Maegaki Y, Haginoya K, Mizumoto S, Kato M, Okamoto N, lai M, Kondo Y, Nishiyama K, Tsurusaki Y, Nakashima M, Miyake N, Hayasaka K, Sugahara K, Yuasa I, Wada Y, Matsumoto N, Saitsu H. De novo mutations in SLC35A2 encoding a UDP-galactose transporter cause early-onset epileptic encephalopathy. Hum Mutat 2013;34:1708-14.

49 Nofrini V, Di Giacomo D, Mecucci C. Nucleoporin genes in human diseases. Eur J Hum Genet 2016;24:1388-95.

50 Tanaka M, Yoshimoto T, Nakamura T. A double-edged sword: the world according to Capicua in cancer. Cancer Sci 2017;108:2319-25.

51 Ramaekers VT, Segers K, Sequeira JM, Koenig M, Van Maldergem L, Bours V, Kornak U, Quadros EV. Genetic assessment and folate receptor autoantibodies in infantile-onset cerebral folate deficiency (CFD) syndrome. Mol Genet Metab 2018;124:87-93.

52 Denny KJ, Kelly CF, Kumar V, Witham KL, Cabrera RM, Finnell RH, Taylor SM, Jeanes A, Woodruff TM. Autoantibodies against homocysteinylated protein in a mouse model of folate deficiency-induced neural tube defects. Birth Defects Res A Clin Mol Teratol 2016;106:201-7.

53 Undas A, Stepień E, Glowacki R, Tisończyk J, Tracz W, Jakubowski H. Folic acid administration and antibodies against homocysteinylated proteins in subjects with hyperhomocysteinemia. Thromb Haemost 2006;96:342-7.

54 Sobreira N, Schiettecatte F, Valle D, Hamosh A. GeneMatcher: a matching tool for connecting Investigators with an interest in the same gene. Hum Mutat 2015;36:928-30.

55 Ramaekers V, Sequeira JM, Quadros EV. Clinical recognition and aspects of the cerebral folate deficiency syndromes. Clin Chem Lab Med 2013;51:497-511.

56 Jay JJ, Brouwer C. Lollipops in the clinic: information dense mutation plots for precision medicine. PLoS One 2016;11:e0160519. 